International Journal of

Molecular Sciences

ISSN 1422-0067

www.mdpi.com/journal/ijms

Review

\title{
Conducting Polymer Nanostructures: Template Synthesis and Applications in Energy Storage
}

Lijia Pan ${ }^{1}$, Hao Qiu ${ }^{1}$, Chunmeng Dou ${ }^{1}$, Yun Li ${ }^{1}$, Lin Pu ${ }^{1}$, Jianbin Xu ${ }^{2}$ and Yi Shi ${ }^{1, *}$

1 National Laboratory of Microstructures (Nanjing), Key Laboratory of Advanced Photonic and Electronic Materials of Jiangsu Province, School of Electronic Science and Engineering, Nanjing University, Nanjing, 210093, Jiangsu Province, China

2 Department of Electronic Engineering, The Chinese University of Hongkong, Shatin, New Territories, Hong Kong, China

* Author to whom correspondence should be addressed; E-Mail: yshi@nju.edu.cn; Tel.: +86-25-866-211-20; Fax: +86-25-866-211-20.

Received: 12 May 2010; in revised form: 29 May 2010 / Accepted: 17 June 2010 /

Published: 2 July 2010

\begin{abstract}
Conducting polymer nanostructures have received increasing attention in both fundamental research and various application fields in recent decades. Compared with bulk conducting polymers, conducting polymer nanostructures are expected to display improved performance in energy storage because of the unique properties arising from their nanoscaled size: high electrical conductivity, large surface area, short path lengths for the transport of ions, and high electrochemical activity. Template methods are emerging for a sort of facile, efficient, and highly controllable synthesis of conducting polymer nanostructures. This paper reviews template synthesis routes for conducting polymer nanostructures, including soft and hard template methods, as well as its mechanisms. The application of conducting polymer mesostructures in energy storage devices, such as supercapacitors and rechargeable batteries, are discussed.
\end{abstract}

Keywords: conducting polymers; nanowires; nanotubes; polyaniline; polypyrrole; template synthesis 


\section{Introduction}

Since the discovery of the first conducting polymer, polyacetylene in 1977, the conducting polymers research field has been established and developed in an unexpectedly accelerated rate [1-5]. Conducting polymers are unique photonic and electronic functional materials owing to their high $\pi$-conjugated length, unusual conducting mechanism, and reversible redox doping/de-doping process. Conducting polymers show various promising applications, such as in transistors [6], sensors [7-10], memories [11], actuators/artificial muscles [12-14], supercapacitors [15], and lithium ionic batteries [16]. In the past decade, conducting polymers nanostructures have become a rapidly growing field of research, because they display new properties related to their nanoscale size and have greatly improved the performance of devices [8,11,17-21]. Conducting polymer nanostructures can be synthesized by several approaches, such as well-controlled solution synthesis [22-25], soft-template methods [26], hard-template methods [27,28], and electrospinning technology [29,30].

In recent years, the low carbon economy of sustainable and renewable resources has become a great challenge due to climate change and the decreasing availability of fossil fuels. It is now essential to develop new, low-cost, and environmentally friendly energy conversion and storage systems. Advances have already been made in energy storage. These include rechargeable lithium batteries and supercapacitors [31-33]. Conducting polymers having good electrochemical activity [34], such as polyaniline, polypyrrole and polythiophene, are important electrode materials for pseudo-capacitors and rechargeable lithium batteries [16,35-37]. Compared with bulk conducting polymers, conducting polymer nanostructures are expected to display improved performance in technological applications [38], because of the unique properties arising from their nanoscale size: (i) high electrical conductivity [39,40]; (ii) large specific surface area [41]; (iii) short path lengths for the transport of ions; (iv) improved cycle life due to better accommodation of the strain caused by electrochemical reaction $[42,43]$; (v) mixed conductive mechanism of both electronic and ionic conductivity, which lowers the interfacial impedance between electrodes and electrolyte; (vi) light weight and large ratio of specific discharge power to weight. Material chemists are attempting to design and synthesize well-structured conducting polymer nanomaterials to realize high-performance supercapacitors and rechargeable lithium batteries. Template synthesis has offered a facile, efficient, and highly controllable route to designing and synthesizing novel conducting polymer nanostructures and composites.

This paper reviews the template synthesis routes for conducting polymer nanostructures, including the soft template, hard template, and reactive template methods and mechanisms. Some selected samples are discussed, particularly with regards to designing and synthesizing fine mesostructures of conducting polymers with high performance in energy storage devices, such as supercapacitors and rechargeable batteries.

\section{Template Directed Growth of Conducting Polymer Nanostructures}

The template synthesizing route of conducting polymer includes soft template and hard template methods. The former relies on molecular self-assembly to form nanostructures, while the latter replicates existing nanostructure by physical or chemical interactions (Scheme 1). 
Scheme 1. Illustration of the template synthesis of conducting polymer nanostructures: 1) soft template method and 2) hard template method. Method 1) includes a) microemulsion and reversed-microemulsion synthesis; and b) non-template (selftemplate) synthesis, in which monomer or oligomer forms structural micelles by themselves. Method 2) includes: c) physical templating against existing nanostructure of particles; d) structural replicate against nanochannels, the method is firstly raised by Prof. C. R. Martin; e) reactive template method, which clone nanostructures by the chemical reaction between template and monomers. Background of the picture is the art "tree-oflife", by Tim Parish in 2008, which is available at: http://torrancepubliclibrary.files.wordpress.com/2009/08/tree-of-life-web.jpg.

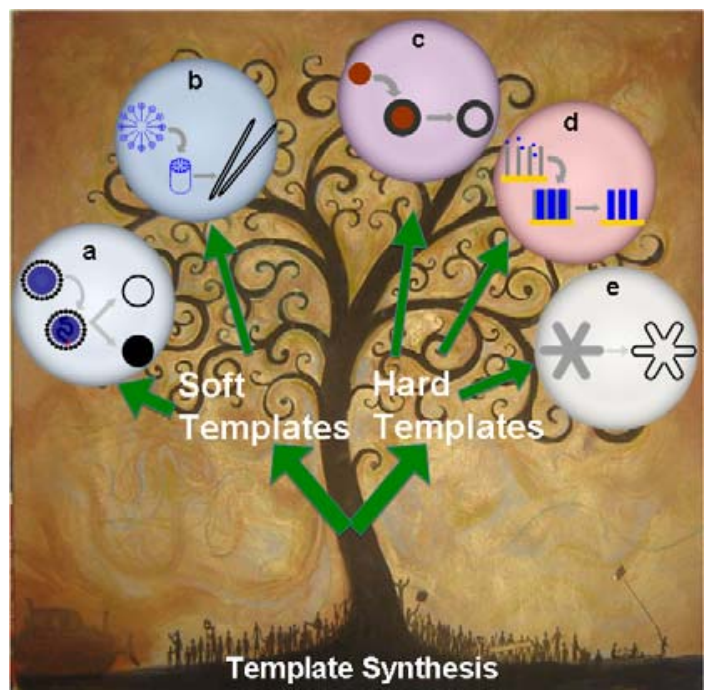

\subsection{Soft Template}

The Soft template synthesis, also named self-assembly method, employs micelles formed by surfactants to confine the polymerization of conducting polymers into low dimensional nanomaterials. Typical synthesis of this sort includes microemulsion polymerization and reversed-microemulsion polymerization [44] in which surfactants are involved, and the non-template (or self-template) synthesis in which the monomer or its salt forms micelles by itself.

Microemulsion (oil-in-water) polymerization produces conducting polymer nanoparticles with good control over the size of nanoparticles. The structure and concentration of surfactants and monomers are critical factors for controlling the morphological parameters of products. Jang et al. synthesized polypyrrole with a monodispersed size in a microemulsion with alkyl-trimethylammonium bromide cationic surfactants [45]. The size of the polypyrrole nanoparticles could be well controlled to be less than $5 \mathrm{~nm}$. They found that the surfactants most suitable for microemulsion polymerization should have alkyl lengths between C6 to $\mathrm{C} 16$ because alkyl chains shorter than C6 have weak hydrophobic interactions, while alkyl chains longer than $\mathrm{C} 16$ have too high a viscosity to form self-assembled nanostructures. Monodispersed polypyrrole nanospheres were synthesized at reagent concentrations between critical the micelle concentration (CMC) I and II. Guo et al. used sodium dodecyl sulfate (SDS, an anionic surfactant) and $\mathrm{HCl}$ solution to control the morphology of polyaniline [46-48]. They 
found that the $\mathrm{pH}$ value of the solution dramatically influenced the self-assembly morphology of the products. Polyaniline in the forms of granules, nanofibers, nanosheets, rectangular submicrotubes, and fanlike/flowerlike aggregates were obtained by using different SDS and $\mathrm{HCl}$ concentrations.

Figure 1. a) Schematic diagram of the microemulsion fabrication of Polypyrrole hollow nanospheres, and their carbon derivative. b-e) transmission electron microscopy (TEM) and scanning electron microscopy (SEM) images of Polypyrrole nanoparticles and hollow spheres: b) soluble Polypyrrole nanoparticles; c) linear Polypyrrole/crosslinked Polypyrrole core/shell nanoparticles; d) Polypyrrole nanocapsules; e) carbon nanocapsule derivative. Reproduced with permission from The Royal Society of Chemistry [49].
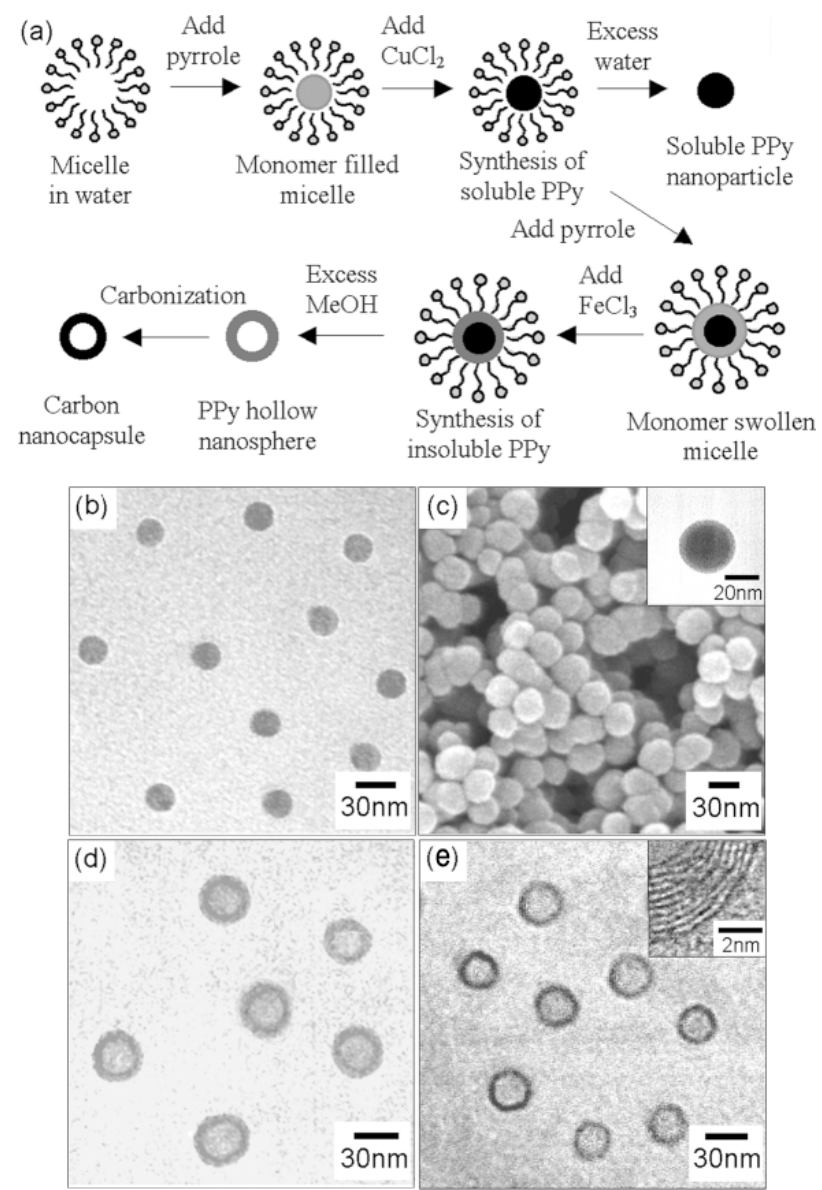

The microemulsion polymerization process can be modified to synthesize nanocapsules, nanocomposite, and mesoporous structures of conducting polymers. Jang et al. produced polypyrrole nanocapsules by generating a soluble polypyrrole core and a crosslinked polypyrrole shell by sequentially using initiators of different oxidation potentials [49], as shown as Figure 1. A linear polypyrrole core soluble in alcohol was produced in the first stage using copper (II) chloride with a lower oxidation potential $\left(E^{\circ}=+0.16 \mathrm{~V}\right)$, while an insoluble crosslinked polypyrrole shell was created in the later stage using iron (III) chloride with higher oxidation potential $\left(E^{\circ}=+0.77 \mathrm{~V}\right)$. Polypyrrole nanocapsules were obtained when excess methyl alcohol was added, which etched the linear polypyrrole core along with the surfactants, and the crosslinked polypyrrole shell was retained. Jang et al. also used surfactant-mediated interfacial polymerization (SMIP) to produce 
poly(3,4-ethylenedioxythiophene) (PEDOT) nanocapsules and mesocellular foams [50]. In the SMIP process, the surfactant micelles were able to capture the redox initiator due to their electrostatic interactions with cations of initiator, and this allowed the initiator to react with the monomer at the micelle/water interface, which generated hollow nanostructures of conductive polymers efficiently.

Reversed microemulsion (water-in-oil) polymerization generates conducting polymer nanostructures such as monodispersed nanoparticles and nanotubes/rods, with morphology controlled by introducing the interaction between ions and surfactant. Jang et al. fabricated polypyrrole nanotubes through chemical oxidation polymerization in sodium bis(2-ethylhexyl) sulfosuccinate (AOT) reverse emulsions in an apolar solvent [51,52], as shown as Figure 2. AOT reverse cylindrical micelles were formed via a cooperative interaction between an aqueous $\mathrm{FeCl}_{3}$ solution and $\mathrm{AOT}$, where $\mathrm{FeCl}_{3}$ aids the formation of rod-shaped micelles by decreasing the CMC II value and increasing the solvent's ionic strength. Pyrrole monomers introduced into the reverse cylindrical micelle phase were then rapidly polymerized by iron cations along the surface of the reverse cylindrical micelles, which resulted in the formation of polypyrrole nanotubes. The residues of AOT and other reagents could be removed by thoroughly washing with excessive ethanol. In a similar method, Manohar et al. obtained PEDOT nanotubes [53]. Jang et al. obtained PEDOT nanorods by chemical oxidation polymerization of the monomer locally on the micelle surface using different reagent concentrations [54]. These researches indicated that the nanostructures of conductive polymers strongly depended on the surfactant concentration and amount of oxidizing agent in reversed microemulsion polymerization.

Surfactant gel is one kind of soft template that can guide the growth of conducting polymers. Polyaniline nanobelts were synthesized by a self-assembly process using the chemical oxidative polymerization of aniline in surfactant gel [55]. In this process, CTAB and aniline self-assembled into belt-like structures, which acted as templates for the formation of polyaniline nanobelts. The subsequent in situ oriented oxidative polymerization of aniline resulted in the formation of polyaniline nanobelts because of the confinement of the surfactant gel.

Some nanostructural morphology of polyaniline could be prepared by the template-free or surfactant-free method (self-template method) [26,56]. In this synthesis, the monomer of conducting polymers or its salts form micelles by themselves, which act as templates for the formation of nanostructures. Wan et al. conducted a thorough research in this field regarding its universality, controllability, and self-assembly mechanism by changing the polymeric chain length, polymerization method, dopant structure, and reaction conditions. They synthesized a variety of micro/nanotubes [57-59], nanofibers, nanotube junctions (Figure 3) [60], and hollow microspheres [61] by the template-free method. The structural parameters of polyaniline nanostructures were tunable by changing dopant structure, the redox potential of the oxidant, and reaction conditions. By varying the reaction temperature or the molar ratio of dopant to aniline, the polyaniline 3D hollow spheres, nanotubes, and dendrites with nanotube junctions could be selectively produced. Some other groups also conducted relative research also [62], Guo et al. developed an efficient method to synthesize poly(o-toluidine) hollow spheres with controllable size and a hole in each single sphere [63,64]. The investigation of these groups shows that the template-free method, which is essentially a kind of a soft-template and self-assembly process, can be a simple and universal approach to synthesizing polyaniline micro/nanostructures [65]. 
Figure 2. a) Schematic diagram of Polypyrrole nanotube fabrication using reverse microemulsion polymerization. b) transmission electron microscopy (TEM) image of Polypyrrole nanotubes. Reproduced with permission from The Royal Society of Chemistry [52].

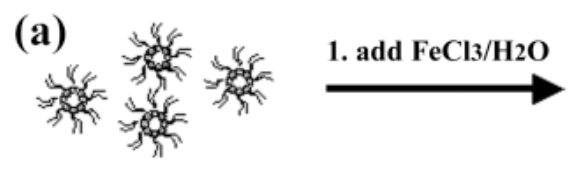

AOT reversed micelles

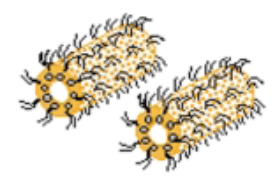

Fe cations trapped by headgroups of AOT

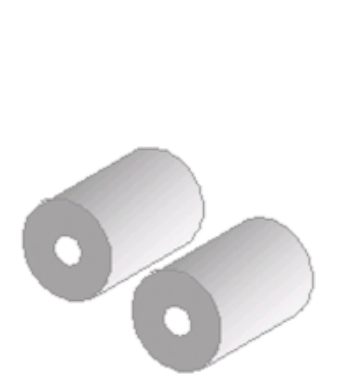

PPy nanotubes

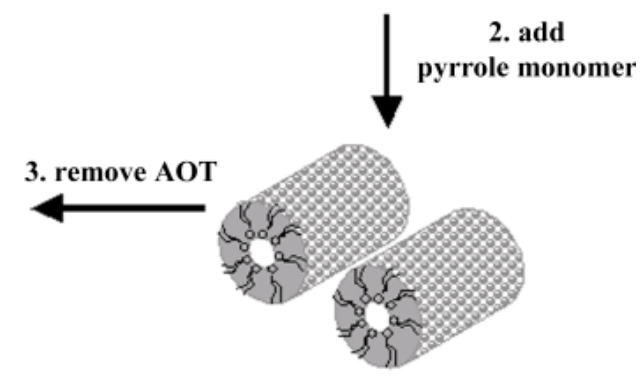

Pyrrole was polymerized along the outside of micelle

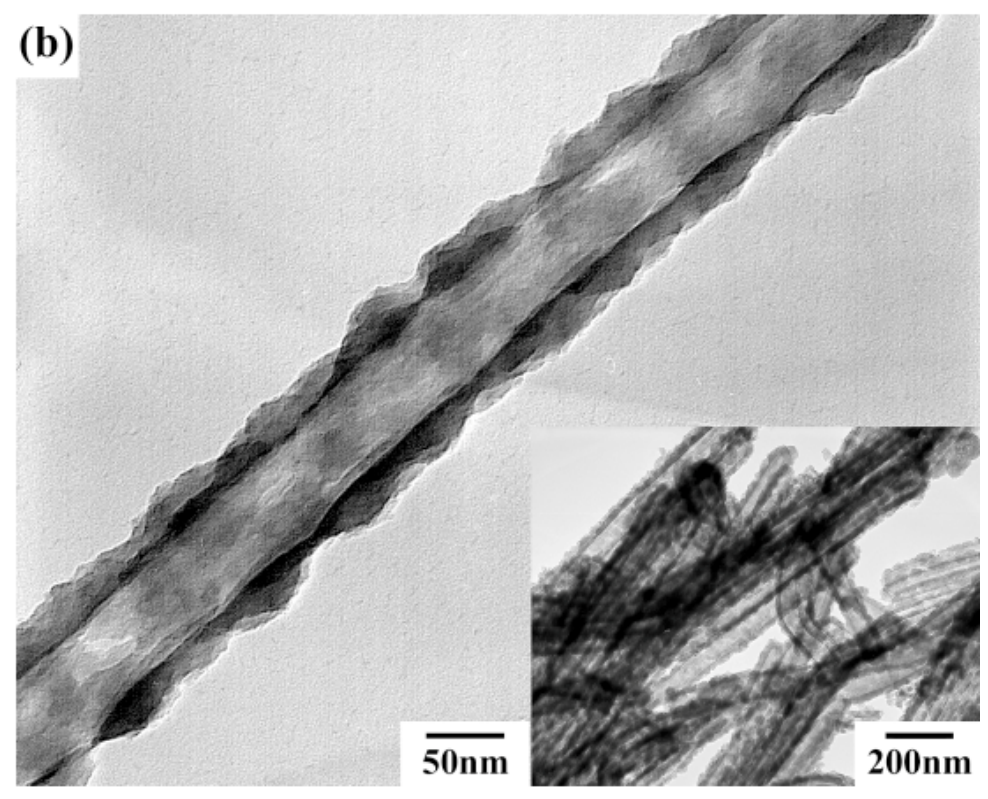

The soft template method owns the advantages of low cost and large yield, which is suitable for the production in large quantities in one pot. Meanwhile, some routes that involve multi-phase solution, such as the microemulsion, reversed-microemulsion and self-template method, have great potential for synthesizing inorganic/conductive-polymer composite nanostructures by interfacial reactions. The shortage of the soft template method in energy storage devices rises from the discontinuous morphology of particles in electrode, which increases the electronic impedance in a certain extent. 
Figure 3. Conductive polymer nanotube junctions and their aggregated dendrites fabricated using non-templating (self-assembly) method: a-c) transmission electron microscopy (TEM) and d) scanning electron microscopy (SEM) image of Polyaniline nanotube junctions; e) SEM image of Polypyrrole dendrite. Reproduced with permission from Wiley-VCH Verlag [60].
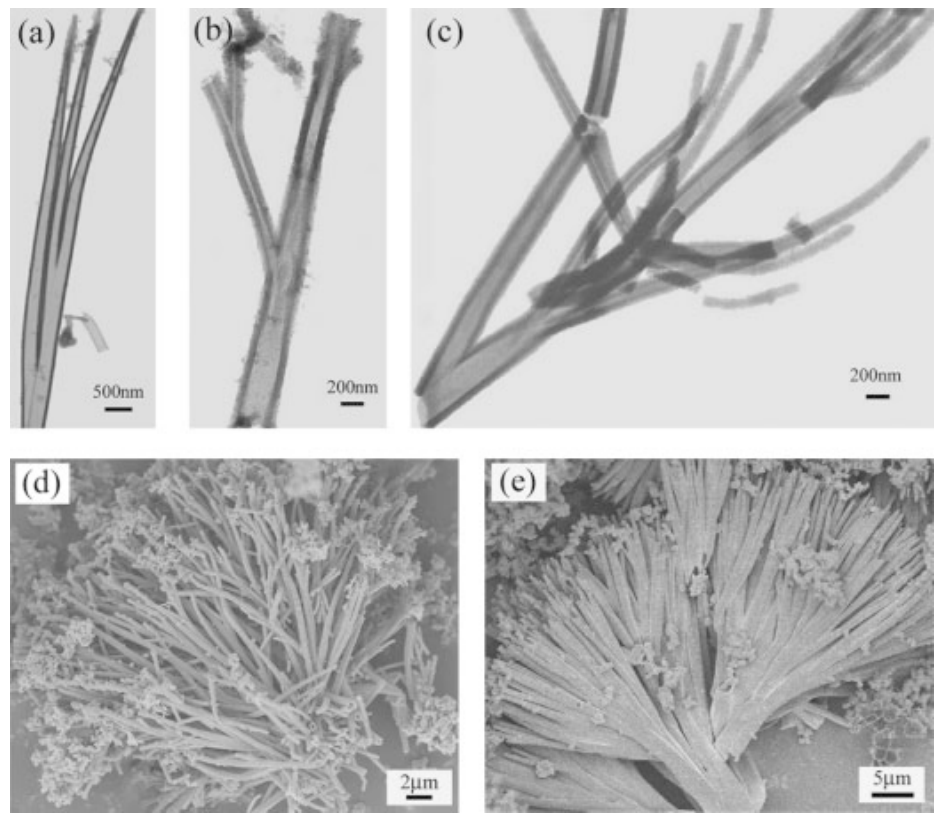

\subsection{Hard Template}

The hard-template synthesis employs a physical template as a scaffold for the growth of conducting polymers. The hard template scaffold includes colloidal particles and some templates with a nanosized channel, such as anodized alumina oxide (AAO) and mesoporous silica/carbon templates [66,67].

For the synthesis using micro/nanoparticles as templates, the target material is precipitated or polymerized on the surface of the template [68], which results in a core-shell structure [69,70]. After removal of the template, hollow nanocapsules or nanotubes can be obtained [71-73]. The most commonly used hard templates include monodispersed inorganic oxide nanoparticles [28,74] and polymer microspheres $[75,76]$. These kinds of templates are advantageous for several reasons: narrow size distribution, ready availability in relatively large amounts, availability in a wide range of sizes from commercial sources, and simplicity of synthesis using well known formulations. However, the removal of the template often affects the hollow structures. Furthermore, the post-processing for template removal is tedious. Wan et al. developed a template self-removing process to produce a polyaniline hollow structure with octahedral cuprous oxide as template as shown as Figure 4, which was spontaneously removed by reaction with an oxidative initiator, ammonium peroxydisulfate [77]. The method simplified the process to produce polyaniline hollow structures in a quantitative way. The only potential drawback of the method is that a reduced emeraldine form of polyaniline was produced because of the reducibility of the cuprous oxide template. 
Figure 4. Polyaniline hollow particle fabricated by the hard template method. a) Scanning electron microscopy (SEM) image of Octahedral $\mathrm{Cu}_{2} \mathrm{O}$ crystal template; b) Polyaniline hollow particle replicates. Reproduced with permission from Wiley-VCH Verlag [77].
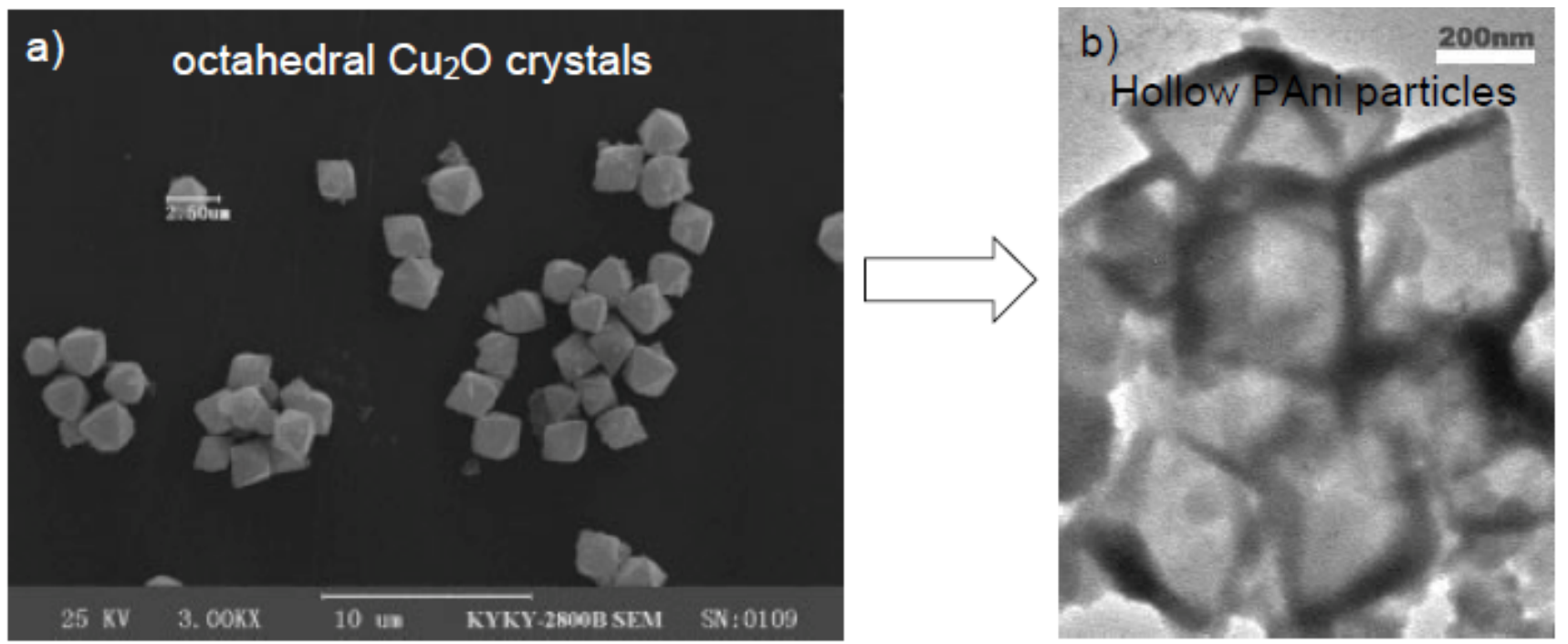

A template with a nanosized channel can be used to produce conducting polymer nanowires/tubes with a restricted deposition/growth effect [41,78-85]. This kind of templating method was first developed by Martin [66,80], and soon became a classic method with highly controllability to produce nanowire/tube nanostructures, and most importantly its arrays. In this approach, the conducting polymer nanostructures can be formed by filling the templates through physical or electrochemical deposition $[82,83,86-88]$. The commonly used and commercially available templates of this sort are anodized alumina oxide membrane [81,89], radiation track-etched polycarbonate (PC) membranes [90-93], zeolite [39], and mesoporous carbon. The AAO template can be used to fabricate conducting polymer composite with well-tuned nanostructures by controlled the electrochemical deposition [94-96]. The first reported transmission electron microscopy (TEM) image of conductive polymer nanotubes using the AAO template by Martin group is shown in Figure 5. One of the most attractive advantages of this route is that the ordered array of conducting polymers nanotubes can be produced using the AAO template [97,98]. Whitesides et al. fabricated core-shell and segmented polymer-metal composite nanostructures by sequentially depositing polyaniline and Au via an electrochemically route [99]. Some mesoporous materials with open nanochannels can be used as template to produce conducting polymer nanofiber or its composites. Bein et al. prepared conducting filaments of polyaniline in the $3 \mathrm{~nm}$ wide hexagonal channel of the aluminosilicate MCM-41 [39]. Aniline vapor was adsorbed onto the dehydrated host. This was followed by a reaction with peroxydisulfate, leading to encapsulated polyaniline filaments. They measured the conductivity of the polymer filaments by contactless microwave absorption at $2.6 \mathrm{GHz}$. The materials showed good low-field conductivity, which demonstrated for the first time that conjugated polymers can be encapsulated in nanometer channels and still support mobile charge carriers. 
Figure 5. Transmission electron microscopy (TEM) image of the conductive polymer nanotubes fabricated using the AAO template. Reproduced with permission from The International Society of Electrochemistry [80].

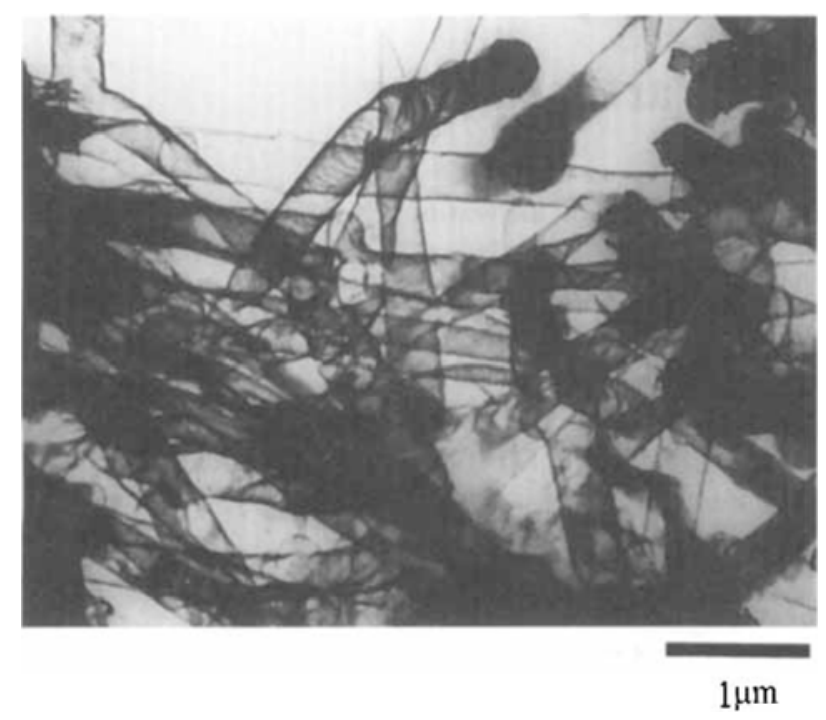

\subsection{Reactive Template and Mechanism Study}

One of the hard templates with highest potential for conducting polymers synthesis is the oxidative inorganic/organic nanostructures, such as the $\mathrm{V}_{2} \mathrm{O}_{5}$ or $\mathrm{MnO}_{2}$ nanowires/fibers. This kind of template can initiate the polymerization of monomers by oxidative reactions, and then effectively transfer their morphology to the conducting polymer. By simply changing the morphology of the reactive template, different sizes and shapes of conducting polymers are possible. The reactive template method is a simple, one-step procedure, since most of the reactive templates could be converted to soluble ions in a redox reaction. As a result, no special purification steps are required to obtain the pure polymer.

$\mathrm{Lu}$ et al. obtained polypyrrole nanotubes by using a fibrillar complex of $\mathrm{FeCl}_{3}$ and methyl orange (MO) as the template [100]. The complex of $\mathrm{FeCl}_{3}$ and $\mathrm{MO}$ could initiate the polymerization of pyrrole monomer and direct the growth of polypyrrole into nanotubes, which self-degraded after the reaction and left azo-functionalized polypyrrole nanotubes in high yield.

Pan et al. developed a reactive template strategy by using manganese oxide nanowires to produce polyaniline nanotubes as shown as Figure 6 [27]. In this case, the $\mathrm{MnO}_{2}$ nanowires served as both oxidative polymerization initiator and physical template. The oxidation potential of $\mathrm{MnO}_{2}$ was sufficient to initiate the polymerization of aniline, and polyaniline films formed on the surface of the $\mathrm{MnO}_{2}$ nanowires as the polymerization proceeded. The morphology of the $\mathrm{MnO}_{2}$ nanowires was thus cloned by polyaniline, which resulted in polyaniline nanotubes with an external size and shape similar in dimensions to that of the $\mathrm{MnO}_{2}$ nanowire template. The reactive template strategy was simple and direct because the reactive $\mathrm{MnO}_{2}$ template could be converted to soluble $\mathrm{Mn}^{2+}$ ions during the polymerization process. As a result, no special purification steps were required to obtain the pure polymer. 
Figure 6. Scanning electron microscopy (SEM) images of a) cryptomelane-phase manganese oxide template, and b) resultant polyaniline nanotubes. The inset of (b) is a transmission electron microscopy (TEM) image of the polyaniline nanotubes. c) Schematic illustration of the formation mechanism of the polyaniline nanotubes. The scale bar is 1 $\mu \mathrm{m}$. Reproduced with permission from Wiley-VCH Verlag [27].

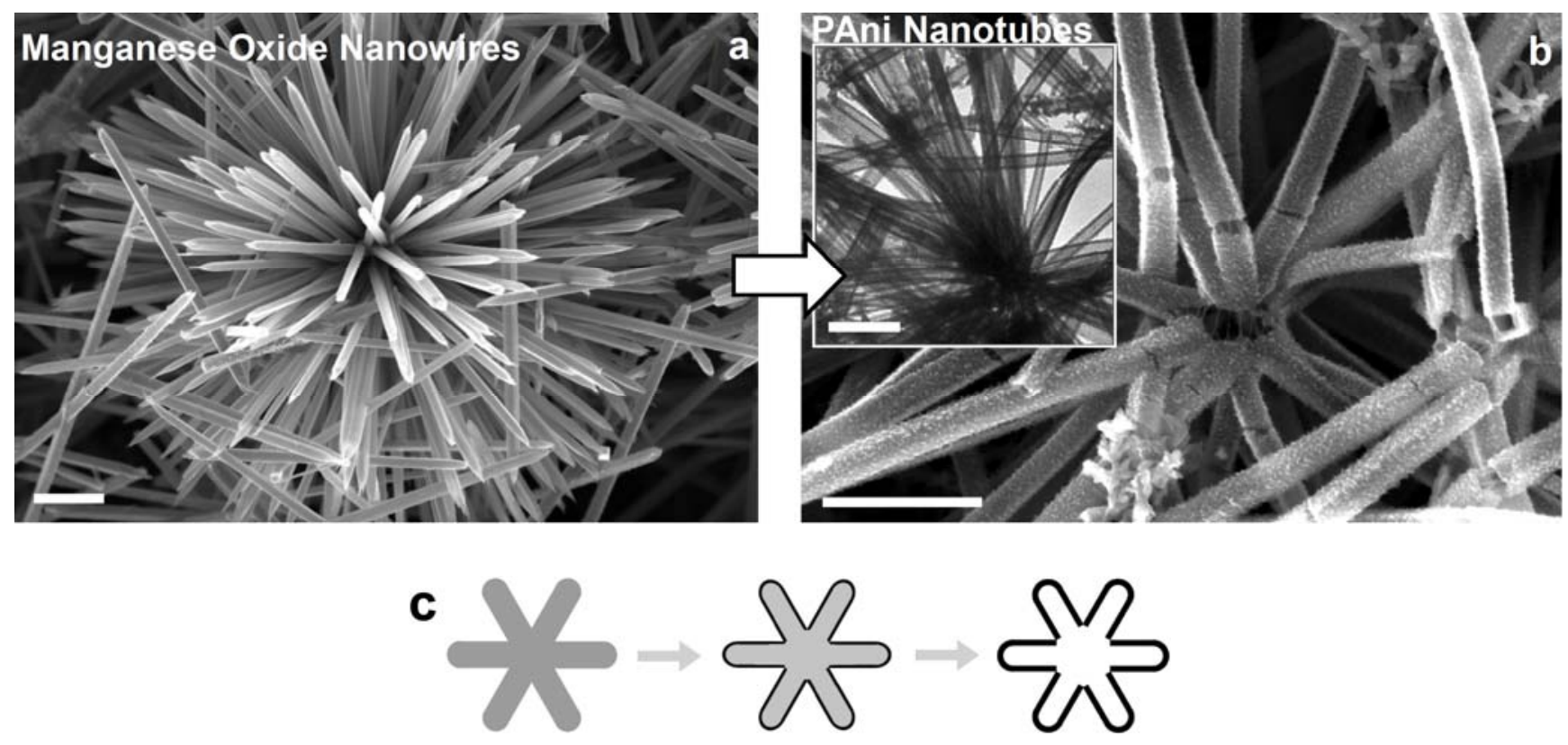

A microzone galvanic cell reaction mechanism contributes to a high quality replica in the reactive template synthesis (Figures 7 and 8, also see the Supporting Information in [27]). TEM investigation of the morphology evolution revealed that the voids of $\mathrm{MnO}_{2}$ were developed inside the nanowires of $\mathrm{MnO}_{2}$ (Figure 7). No polyaniline was polymerized in the inner surface of the voids, while polyaniline is homogeneously grown on the outer surface of $\mathrm{MnO}_{2}$ nanowires (with no dependence on the local $\mathrm{MnO}_{2}$ consumed). The reaction is schematically illustrated as the two half-cell reactions in Figure 8, which is the typical reaction mode of a microzone galvanic cell. The reaction is caused by differences in local chemical environment. This microzone galvanic cell reaction mechanism enables the high-fidelity replication of the structure of manganese by polyaniline. Furthermore, the microzone galvanic cell reaction mechanism has a great potential for the fabrication of nanostructures or novel nanocomposites.

The reactive template method presents a strong potential for shape controlling. Different polyaniline nanosizes and shapes are possible by simply changing the morphology of the $\mathrm{MnO}_{2}$ template, for example, Li et al. prepared spherical and cubic hollow structures of polyaniline and polypyrrole by using a structured $\mathrm{MnO}_{2}$ template [101].

In recent years, the hard-template synthesis has received increasing interest for energy storage devices, due to the following reasons: (i) hard-template synthesis has provided a strong tool to produce arrayed conductive polymer nanowires/tubes, which improve ionic change of electrode materials and electronic transport to the collector; (ii) hard-template synthesis is an easy way to produce inorganic/organic composite nanostructures, which show high performance in supercapacitors and batteries. 
Figure 7. Transmission electron microscopy (TEM) images show the structural evolution during the conversion from cryptomelane phase manganese nanowires to polyaniline nanotubes after: a) $60 \mathrm{~s}$; b) $180 \mathrm{~s}$; and c) $480 \mathrm{~s}$. d) the magnified image of the root region of (b). e), f) HRTEM (high-resolution TEM) images indicate the formation of polyaniline (shell)/manganese oxide (core) composite tube in the corrosive etching of manganese oxide. The scale bar is $1 \mu \mathrm{m}$. Reproduced with permission from Wiley-VCH Verlag [27].
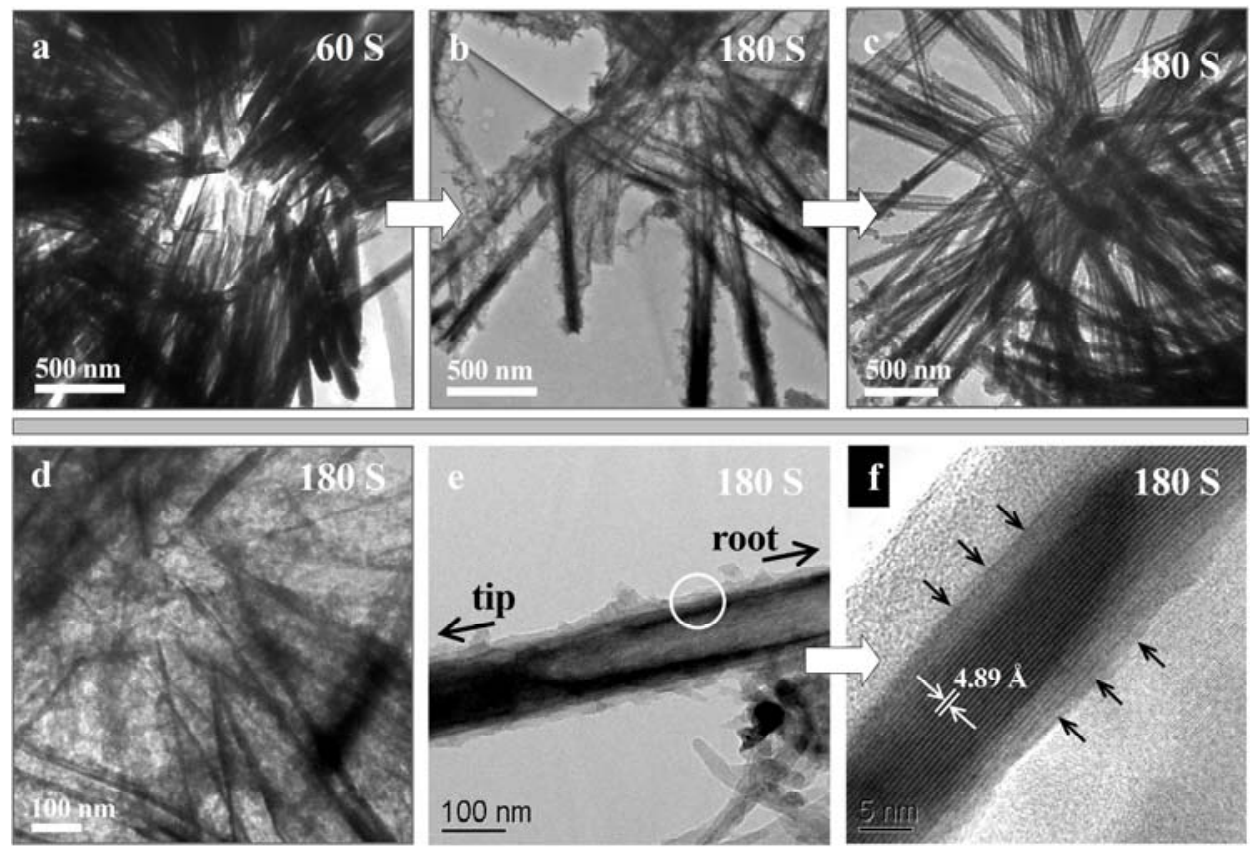

Figure 8. Schematic illustration of the proposed microzone galvanic cell reaction that occurs during the conversion from manganese oxide wire to polyaniline nanotube. a) The aniline was polymerized on a manganese oxide nanowire surface. b) The hollow structure developed mainly through the micro-zone galvanic-cell reaction mode. c) The homogeneous polyaniline tube was finally formed because the whole surface of the polyaniline (Polyaniline) thin film was almost equipotential in the micro-zone galvaniccell reaction. Reproduced with permission from Wiley-VCH Verlag [27].

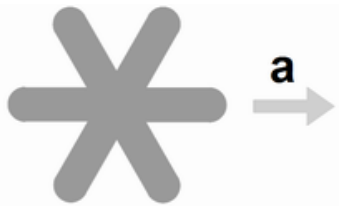

Anode reaction: $n$ aniline $\rightarrow$ PAni $+k$ e

Cathode Reaction:

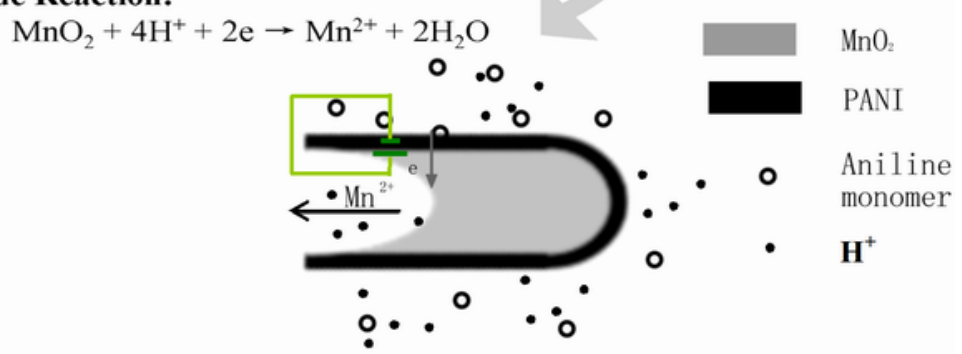


In general, template synthesis has offered chemists a more flexible and efficient route to synthesize well-defined conducting polymer nanostructures. Meanwhile, the nanostructure synthesized by template synthesis shows some improved physical properties that show great potential for its application in energy storage devices, for example, conductivity at room temperature. Martin and his group found that template-synthesized conducting polymer tubes or fibrils have enhanced conductivity as compared with bulk materials. The nanotubes have enhanced conductivity because the conductive polymer as synthesized has high molecular and supermolecular order. The Martin group proposed several mechanisms for the formation of the high ordering of the conductive polymer: 1) the chain of conductive polymer deposited in the nanochannels oriented according to the ordering of the polycarbonates molecules in membrane wall; 2) the polycationic conductive polymer preferentially polymerizes on the anionic sites on the pores of polycarbonates membrane; 3) the chain ordering of conductive polymer is induced by the confined synthesis into nanopores acting as nanoreactor [102-105]. Meanwhile, it was found that the conductivity is enhanced with decreasing pore diameter [17,106-111]. A dramatic change in conduction behavior from an insulating regime to a metallic regime through the critical regime as diameter decreases.

\section{High-Power Energy Storage Devices: Supercapacitors and Batteries}

Conducting polymers are important electrode materials for electrochemical energy storage devices[112], such as supercapacitors [31] and lithium secondary batteries [113]. There are several potential advantages associated with the development of conducting polymers nanoelectrodes for these devices: (i) higher electrode/electrolyte contact area leading to higher charge/discharge rates; (ii) short path lengths for electronic transport (permitting operation with low electronic conductivity or at higher power); (iii) short path lengths for the transport of ions; and (iv) better accommodation of the strain of the electrochemical reaction to improve cycle life. Template synthesis has offered chemists a more flexible and efficient route to synthesizing well-designed conducting polymer nanostructures with improved electrochemical energy storage [114]. Some typical examples are discussed below:

Lee et al. synthesized the composites of PEDOT and $\mathrm{MnO}_{2}$ nanowires by a one step electrochemical co-deposition in an AAO template, as shown as Figure 9 [115]. The composite nanowire had a coaxial structure with PEDOT as the shell and $\mathrm{MnO}_{2}$ as the core. The coaxial nanowires could be used as excellent supercapacitor materials, which not only exhibited high specific capacitance values but also showed a greatly improved ability to maintain capacitance at high current density, preserving $85 \%$ of its specific capacitance as the current density increased from 5 to $25 \mathrm{~mA} / \mathrm{cm}^{2}$. The well-maintained specific capacitance was mainly attributed to the short paths of ion diffusion in the nanowires, wherein the porous nature of the PEDOT shell allowed for fast ion diffusion into the $\mathrm{MnO}_{2}$ core. On the other hand, the highly electrical conducting PEDOT shell facilitated electron transport to the $\mathrm{MnO}_{2}$ core, which increased the conductivity of the coaxial nanowire. The electrochemical capacitance of nanowire materials could be fully utilized, especially for the performance at high current density, due to its well-tuned microstructure, which is crucial for high power demand when operating at high charge and discharge rates. 
Figure 9. a) Schematic illustration of the formation mechanism of $\mathrm{MnO}_{2} / \mathrm{PEDOT}$ composite nanowires; b) Scanning electron microscopy (SEM) image of $\mathrm{MnO}_{2} / \mathrm{PEDOT}$ coaxial nanowires $(0.75 \mathrm{~V})$. c) Transmission electron microscopy (TEM) image from a single coaxial nanowire $(0.75 \mathrm{~V})$. $\mathbf{d}$ and $\mathbf{e})$ Energy Dispersive Spectroscopy (EDS) maps of $\mathrm{S}$ and $\mathrm{Mn}$ from the boxed area in Figure 9c. Reproduced with permission from The American Chemical Society [115].
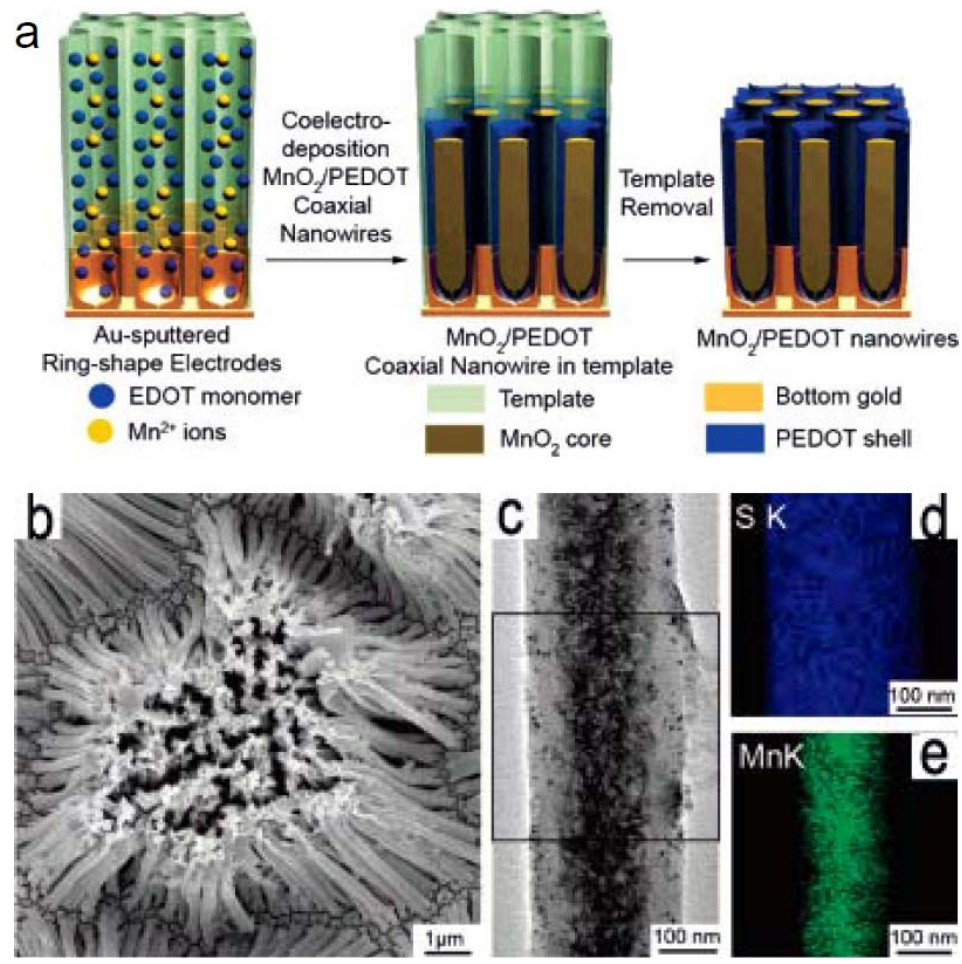

Composites of conducting polymers and mesoporous carbon have great potential applications for energy storage devices because mesoporous carbon backbone can provide a material with good stability and increased electronic conductivity, while conducting polymers provide electrochemical activity. Moreover, the discovery that ion desolvation occurs in pores smaller than the solvated ions has led to higher capacitance for electrochemical double layer capacitors using carbon electrodes with subnanometer pores, and opened the door to designing high-energy density devices with mesoporous carbon materials. Xia et al. reported the growth of ordered whisker-like polyaniline on the surface of a mesoporous carbon template and its excellent supercapacitor properties [15]. The nanosize polyaniline thorns were polymerized on a mesoporous carbon surface, and formed "V-type" nanopores as show as Figure 10. These nanopores yielded high electrochemical capacitance because the "V-type" channels facilitated faster penetration of the electrolyte and the shorter diffusion length of ions within the electrode during the charge-discharge process. On the other hand, the high conductivity of polyaniline and mesoporous carbon greatly reduced energy loss and power loss at high charge-discharge current density. The specific capacitance of the polyaniline/mesoporous carbon composite was as high as $900 \mathrm{~F} \mathrm{~g}^{-1}$ at a charge-discharge current density of $0.5 \mathrm{~A} \mathrm{~g}^{-1}$ (or $1221 \mathrm{~F} \mathrm{~g}^{-1}$ for polyaniline, based on pure polyaniline in the composite). This was a significant progress on supercapacitor research because the capacitance value was higher than that of amorphous hydrated $\mathrm{RuO}_{2}\left(840 \mathrm{~F} \mathrm{~g}^{-1}\right)$, while polyaniline is much cheaper than $\mathrm{RuO}_{2}$. Furthermore, the capacitance retention of this composite was higher than 
$85 \%$ when the charge-discharge current density increased from $0.5 \mathrm{Ag}^{-1}$ to $5 \mathrm{Ag}^{-1}$, indicating its potential high power performance while operating at high charge and discharge rates.

Figure 10. a) The illustration of the synthetic route of Wang to well structured conducting polymers and mesoporous carbon. b) SEM image of mesoporous carbon product; c, d) TEM images of mesoporous carbon seen from the [001] and [100] directions; e) SEM image of POLYANILINE/mesoporous carbon product; f, g) TEM images of POLYANILINE/mesoporous carbon at different magnifications. Reproduced with permission from Wiley-VCH Verlag [15].

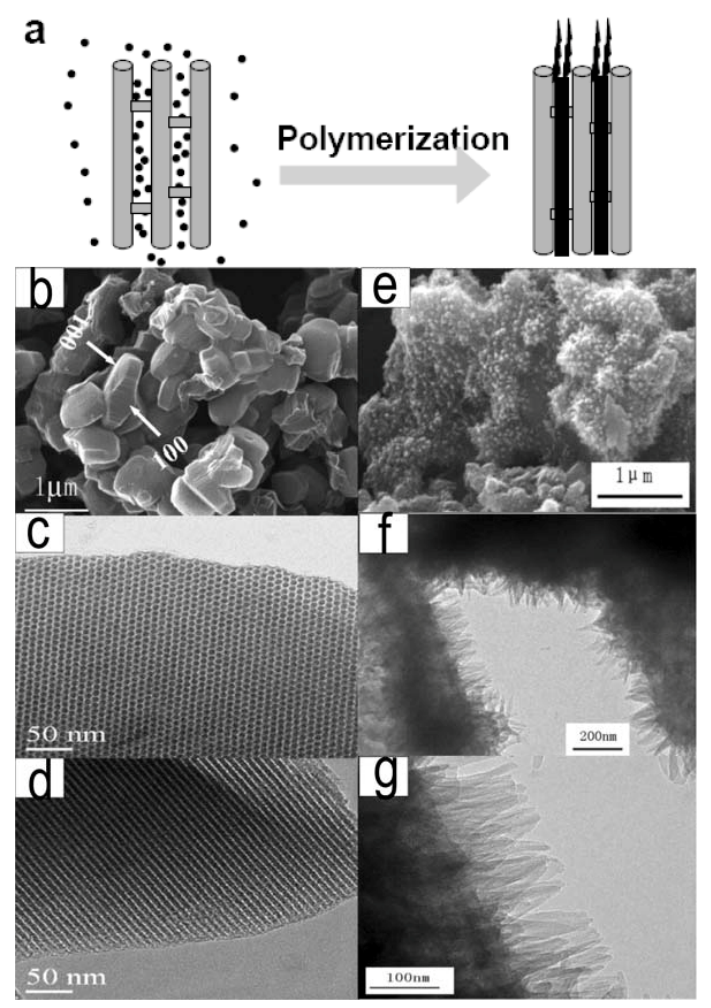

Arrayed conducting polymer nanotube/fibers were produced within an APA template by both physical and electrochemical deposition. It has led to greatly improved properties of rechargeable batteries. Chen et al. produced polyaniline nanofibers and nanotubes using a spray technique by wetting the APA template with a conducting polymers solution [116]. The nanofibers/tubes showed excellent electrochemical performance when used as a positive electrode material in lithium batteries. The discharge capacity value of the doped polyaniline nanotubes/nanofibers reached $75.7 \mathrm{~mA} \mathrm{~h} \mathrm{~g}^{-1}$, and retained $72.3 \mathrm{~mA} \mathrm{~h} \mathrm{~g}^{-1}$ (95.5\% of the highest discharge capacity) in the 80th cycle. The discharge capacity of polyaniline nanotubes is much higher than the best practical discharge capacity of the commercially doped polyaniline powders $\left(54.2 \mathrm{~mA} \mathrm{~h} \mathrm{~g}^{-1}\right)$. Meanwhile, the specific discharge energy of the nanostructures reached $227 \mathrm{~W} \mathrm{~h} \mathrm{Kg}^{-1}$, showing excellent storage of high specific energy for Li/polyaniline rechargeable cells. The average capacity deterioration of the nanostructural doped polyaniline was less than $0.05 \mathrm{~mA} \mathrm{~h} \mathrm{~g}^{-1}$ for one cycle, indicating their superior cycling capability. In addition, the nanotube electrode exhibited longer charge and discharge plateaus than the electrode composed of commercial powders. All these indicate the great potential application of polyaniline nanotubes synthesized by template method as high performance cathode-active 
materials for $\mathrm{Li} /$ polyaniline rechargeable batteries. Moreover, the composite of nanostructured polyaniline and $\mathrm{V}_{2} \mathrm{O}_{5}$ showed a potential application in lithium secondary battery. Li et al. fabricated uniform one-dimensional $\mathrm{V}_{2} \mathrm{O}_{5}$ /polyaniline core-shell nanobelts by using $\mathrm{V}_{2} \mathrm{O}_{5}$ nanobelt as a reactive template [117]. The formation of the $\mathrm{V}_{2} \mathrm{O}_{5}$ /polyaniline core-shell nanobelts was related to the in situ polymerization of aniline monomer through etching $\mathrm{V}_{2} \mathrm{O}_{5}$ nanobelts. They studied the electrochemical lithium intercalation/deintercalation of $\mathrm{V}_{2} \mathrm{O}_{5}$ /polyaniline core-shell nanobelts and showed that the material can be used in lithium secondary batteries.

\section{Conclusions}

Climate change and the rapidly decreasing availability of fossil fuels require society to move in an accelerating speed towards the use of sustainable and renewable resources. Supercapacitor and lithium batteries are two important devices for energy storage and release. The design and bulky fabrication of fine nanostructures of conducting polymers and composites is the key to success in designing tomorrow's high-energy and high-power devices. This review strongly suggests the use of the template method as a simple, universal, and controlled approach to fabricate novel conducting polymer nanostructures and composites. Furthermore, some cases on designing and synthesizing fine mesostructures of conducting polymer with high performance in energy storage devices, were discussed.

\section{Acknowledgements}

We wish to thank the financial support provided by the National Key Fundamental Research Project (No. 2007CB936300), NSFC (No. 60706019 and 60928009), NSFJS (No. BK2007146, BK2008025), and the Program for New Century Excellent Talents in University.

\section{References}

1. Heeger, A.J. Semiconducting and metallic polymers: The fourth generation of polymeric materials (Nobel lecture). Angew. Chem.: Int. Edit. 2001, 40, 2591-2611.

2. MacDiarmid, A.G. "Synthetic metals": A novel role for organic polymers (Nobel lecture). Angew. Chem.: Int. Edit. 2001, 40, 2581-2590.

3. Shirakawa, H. The discovery of polyacetylene film: The dawning of an era of conducting polymers (Nobel lecture). Angew. Chem.-Int. Edit. 2001, 40, 2575-2580.

4. Lee, K.; Cho, S.; Park, S.H.; Heeger, A.J.; Lee, C.W.; Lee, S.H. Metallic transport in polyaniline. Nature 2006, 441, 65-68.

5. Zhang, L.P.; Peng, H.; Kilmartin, P.A.; Soeller, C.; Travas-Sejdic, J. Poly (3.4ethylenedioxythiophene) and polyaniline bilayer nanostructures with high conductivity and electrocatalytic activity. Macromolecules 2008, 41, 7671-7678.

6. Aleshin, A.N. Polymer nanofibers and nanotubes: Charge transport and device applications. Adv. Mater. 2006, 18, 17-27.

7. Virji, S.; Huang, J.X.; Kaner, R.B.; Weiller, B.H. Polyaniline nanofiber gas sensors: Examination of response mechanisms. Nano Lett. 2004, 4, 491-496. 
8. Huang, J.X.; Virji, S.; Weiller, B.H.; Kaner, R.B. Polyaniline nanofibers: Facile synthesis and chemical sensors. J. Am. Chem. Soc. 2003, 125, 314-315.

9. Alici, G.; Spinks, G.M.; Madden, J.D.; Wu, Y.Z.; Wallace, G.G. Response characterization of electroactive polymers as mechanical sensors. IEEE-ASME Trans. Mechatron. 2008, 13, 187-196.

10. Hui, P.; Lijuan, Z.; Soeller, C.; Travas-Sejdic, J. Conducting polymers for electrochemical DNA sensing. Biomaterials 2009, 30, 2132-2148.

11. Tseng, R.J.; Huang, J.X.; Ouyang, J.; Kaner, R.B.; Yang, Y. Polyaniline nanofiber/gold nanoparticle nonvolatile memory. Nano Lett. 2005, 5, 1077-1080.

12. Baker, C.O.; Shedd, B.; Innis, P.C.; Whitten, P.G.; Spinks, G.M.; Wallace, G.G.; Kaner, R.B. Monolithic actuators from flash-welded polyaniline nanofibers. Adv. Mater. 2008, 20, 155-158.

13. Spinks, G.M.; Mottaghitalab, V.; Bahrami-Saniani, M.; Whitten, P.G.; Wallace, G.G. Carbonnanotube-reinforced polyaniline fibers for high-strength artificial muscles. Adv. Mater. 2006, 18, 637-640.

14. Wu, Y.; Alici, G.; Spinks, G.M.; Wallace, G.G. Fast trilayer polypyrrole bending actuators for high speed applications. Synth. Met. 2006, 156, 1017-1022.

15. Wang, Y.G.; Li, H.Q.; Xia, Y.Y. Ordered whiskerlike polyaniline grown on the surface of mesoporous carbon and its electrochemical capacitance performance. Adv. Mater. 2006, 18, 2619-2623.

16. Oyama, N.; Tatsuma, T.; Sato, T.; Sotomura, T. Dimercaptan-polyaniline composite electrodes for lithium batteries with high-energy density. Nature 1995, 373, 598-600.

17. Long, Y.Z.; Duvail, J.L.; Li, M.M.; Gu, C.Z.; Liu, Z.W.; Ringer, S.P. Electrical conductivity studies on individual conjugated polymer nanowires: Two-probe and four-probe results. Nanoscale Res. Lett. 2010, 5, 237-242.

18. Long, Y.Z.; Zhang, L.J.; Chen, Z.J.; Huang, K.; Yang, Y.S.; Xiao, H.M.; Wan, M.X.; Jin, A.Z.; $\mathrm{Gu}, \mathrm{C} . \mathrm{Z}$. Electronic transport in single polyaniline and polypyrrole microtubes. Phys. Rev. B 2005, 71, 165412:1-165412:7.

19. Pan, L.J.; Pu, L.; Shi, Y.; Sun, T.; Zhang, R.; Zheng, Y.D. Hydrothermal synthesis of polyaniline mesostructures. Adv. Funct. Mater. 2006, 16, 1279-1288.

20. Forzani, E.S.; Zhang, H.Q.; Nagahara, L.A.; Amlani, I.; Tsui, R.; Tao, N.J. A conducting polymer nanojunction sensor for glucose detection. Nano Lett. 2004, 4, 1785-1788.

21. Chiou, N.R.; Lui, C.M.; Guan, J.J.; Lee, L.J.; Epstein, A.J. Growth and alignment of polyaniline nanofibres with superhydrophobic, superhydrophilic and other properties. Nat. Nanotechnol. 2007, 2, 354-357.

22. Huang, J.X.; Kaner, R.B. Nanofiber formation in the chemical polymerization of aniline: A mechanistic study. Angew. Chem.: Int. Edit. 2004, 43, 5817-5821.

23. Li, D.; Kaner, R.B. Shape and aggregation control of nanoparticles: Not shaken, not stirred. $J$. Am. Chem. Soc. 2006, 128, 968-975.

24. Laslau, C.; Zujovic, Z. D.; Travas-Sejdic, J. Polyaniline "nanotube" self-assembly: the stage of granular agglomeration on nanorod templates. Macromol. Rapid Commun. 2009, 30, 1663-1668.

25. Chiou, N.R.; Epstein, A.J. Polyaniline nanofibers prepared by dilute polymerization. Adv. Mater. 2005, 17, 1679-1683. 
26. Wan, M.X. A template-free method towards conducting polymer nanostructures. Adv. Mater. 2008, 20, 2926-2932.

27. Pan, L.J.; Pu, L.; Shi, Y.; Song, S.Y.; Xu, Z.; Zhang, R.; Zheng, Y.D. Synthesis of polyaniline nanotubes with a reactive template of manganese oxide. Adv. Mater. 2007, 19, 461-464.

28. Yang, M.; Ma, J.; Zhang, C.L.; Yang, Z.Z.; Lu, Y.F. General synthetic route toward functional hollow spheres with double-shelled structures. Angew. Chem.: Int. Edit. 2005, 44, 6727-6730.

29. Yu, J.H.; Fridrikh, S.V.; Rutledge, G.C. Production of submicrometer diameter fibers by twofluid electrospinning. Adv. Mater. 2004, 16, 1562-1566.

30. Shin, M.K.; Kim, Y.J.; Kim, S.I.; Kim, S.K.; Lee, H.; Spinks, G.M.; Kim, S.J. Enhanced conductivity of aligned Polyaniline/PEO/MWNT nanofibers by electrospinning. Sens. Actuat. B: Chem. 2008, 134, 122-126.

31. Simon, P.; Gogotsi, Y. Materials for electrochemical capacitors. Nat. Mater. 2008, 7, 845-854.

32. Arico, A.S.; Bruce, P.; Scrosati, B.; Tarascon, J.M.; van Schalkwijk, W. Nanostructured materials for advanced energy conversion and storage devices. Nat. Mater. 2005, 4, 366-377.

33. Wang, C.Y.; Mottaghitalab, V.; Too, C.O.; Spinks, G.M.; Wallace, G.G. Polyaniline and polyaniline-carbon nanotube composite fibres as battery materials in ionic liquid electrolyte. $J$. Power Sources 2007, 163, 1105-1109.

34. Smela, E.; Inganas, O.; Lundstrom, I. Controlled folding of micrometer-size structures. Science 1995, 268, 1735-1738.

35. Novak, P.; Muller, K.; Santhanam, K.S.V.; Haas, O. Electrochemically active polymers for rechargeable batteries. Chem. Rev. 1997, 97, 207-281.

36. Ryu, K.S.; Jeong, S.K.; Joo, J.; Kim, K.M. Polyaniline doped with dimethyl sulfate as a nucleophilic dopant and its electrochemical properties as an electrode in a lithium secondary battery and a redox supercapacitor. J. Phys. Chem. B 2007, 111, 731-739.

37. Ryu, K.S.; Kim, K.M.; Kang, S.G.; Lee, G.J.; Joo, J.; Chang, S.H. Electrochemical and physical characterization of lithium ionic salt doped polyaniline as a polymer electrode of lithium secondary battery. Synth. Met. 2000, 110, 213-217.

38. Zhang, F.L.; Nyberg, T.; Inganas, O. Conducting polymer nanowires and nanodots made with soft lithography. Nano Lett. 2002, 2, 1373-1377.

39. Wu, C.G.; Bein, T. Conducting polyaniline filaments in a mesoporous channel host. Science 1994, 264, 1757-1759.

40. Yin, Z.H.; Long, Y.Z.; Gu, C.Z.; Wan, M.X.; Duvail, J.L. Current-Voltage Characteristics in Individual Polypyrrole Nanotube, Poly(3,4-ethylenedioxythiophene) Nanowire, Polyaniline Nanotube, and CdS Nanorope. Nanoscale Res. Lett. 2009, 4, 63-69.

41. Penner, R.M.; Martin, C.R. Microporous membrane-modified electrodes for preparation of chemical microstructures on electrode surfaces. J. Electrochem. Soc. 1987, 134, C504-C504.

42. Pei, Q.B.; Inganas, O. Electrochemical applications of the bending beam method .1. masstransport and volume changes in polypyrrole during redox. J. Phys. Chem. 1992, 96, 10507-10514.

43. Pei, Q.B.; Inganas, O. Electrochemical applications of the bending beam method .2. electroshrinking and slow relaxation in polypyrrole. J. Phys. Chem. 1993, 97, 6034-6041.

44. Wessling, B. Dissipative structure formation in colloidal systems. Adv. Mater. 1993, 5, 300-305. 
45. Jang, J.; Oh, J.H.; Stucky, G.D. Fabrication of ultrafine conducting polymer and graphite nanoparticles. Angew. Chem.: Int. Edit. 2002, 41, 4016-4019.

46. Zhou, C.Q.; Han, J.; Guo, R. Polyaniline Fan-Like Architectures of Rectangular Sub-Microtubes Synthesized in Dilute Inorganic Acid Solution. Macromol. Rapid Commun. 2009, 30, 182-187.

47. Zhou, C.Q.; Han, J.; Guo, R. Synthesis of polyaniline hierarchical structures in a dilute sds/hcl solution: nanostructure-covered rectangular tubes. Macromolecules 2009, 42, 1252-1257.

48. Zhou, C.Q.; Han, J.; Guo, R. Dilute anionic surfactant solution route to polyaniline rectangular sub-microtubes as a novel nanostructure. J. Phys. Chem. B 2008, 112, 5014-5019.

49. Jang, J.; Li, X.L.; Oh, J.H. Facile fabrication of polymer and carbon nanocapsules using polypyrrole core/shell nanomaterials. Chem. Commun. 2004, 7, 794-795.

50. Jang, J.; Bae, J.; Park, E. Selective fabrication of poly (3,4-ethylenedioxythiophene) nanocapsules and mesocellular foams using surfactant-mediated interfacial polymerization. Adv. Mater. 2006, 18, 354-358.

51. Jang, J.; Yoon, H. Formation mechanism of conducting polypyrrole nanotubes in reverse micelle systems. Langmuir 2005, 21, 11484-11489.

52. Jang, J.; Yoon, H. Facile fabrication of polypyrrole nanotubes using reverse microemulsion polymerization. Chem. Commun. 2003, 6, 720-721.

53. Zhang, X.Y.; Lee, J.S.; Lee, G.S.; Cha, D.K.; Kim, M.J.; Yang, D.J.; Manohar, S.K. Chemical synthesis of PEDOT nanotubes. Macromolecules 2006, 39, 470-472.

54. Yoon, H.; Hong, J.Y.; Jang, J. Charge-transport behavior in shape-controlled poly(3,4ethylenedioxythiophene) nanomaterials: Intrinsic and extrinsic factors. Small 2007, 3, 1774-1783.

55. Li, G.C.; Peng, H.R.; Wang, Y.; Qin, Y.; Cui, Z.L.; Zhang, Z.K. Synthesis of polyaniline nanobelts. Macromol. Rapid Commun. 2004, 25, 1611-1614.

56. Wan, M.X. Some Issues Related to Polyaniline Micro-/Nanostructures. Macromol. Rapid Commun. 2009, 30, 963-975.

57. Zhang, Z.M.; Wan, M.X.; Wei, Y. Highly crystalline polyaniline nanostructures doped with dicarhoxylic acids. Adv. Funct. Mater. 2006, 16, 1100-1104.

58. Zhang, L.J.; Wan, M.X. Self-assembly of polyaniline - From nanotubes to hollow microspheres. Adv. Funct. Mater. 2003, 13, 815-820.

59. Qiu, H.J.; Wan, M.X.; Matthews, B.; Dai, L.M. Conducting polyaniline nanotubes by templatefree polymerization. Macromolecules 2001, 34, 675-677.

60. Wei, Z.X.; Zhang, L.J.; Yu, M.; Yang, Y.S.; Wan, M.X. Self-assembling sub-micrometer-sized tube junctions and dendrites of conducting polymers. Adv. Mater. 2003, 15, 1382-1385.

61. Zhu, Y.; Hu, D.; Wan, M.X.; Jiang, L.; Wei, Y. Conducting and superhydrophobic rambutan-like hollow spheres of polyaniline. Adv. Mater. 2007, 19, 2092-2096.

62. Jing, S.; Lijuan, Z.; Hui, P.; Travas-Sejdic, J.; Kilmartin, P.A. Self-assembly of poly(omethoxyaniline) hollow nanospheres from a polymeric acid solution. Nanotechnology 2009, 20, 415606-415614.

63. Han, J.; Song, G.P.; Guo, R. A facile solution route for polymeric hollow spheres with controllable size. Adv. Mater. 2006, 18, 3140-3144. 
64. Han, J.; Song, G.P.; Guo, R. Synthesis of polymer hollow spheres with holes in their surfaces. Chem. Mat. 2007, 19, 973-975.

65. Zhang, L.J.; Zujovic, Z.A.; Peng, H.; Bowmaker, G.A.; Kilmartin, P.A.; Travas-Sejdic, J. Structural characteristics of polyaniline nanotubes synthesized from different buffer solutions. Macromolecules 2008, 41, 8877-8884.

66. Cai, Z.H.; Martin, C.R. Electronically conductive polymer fibers with mesoscopic diameters show enhanced electronic conductivities. J. Am. Chem. Soc. 1989, 111, 4138-4139.

67. Martin, C.R.; Vandyke, L.S.; Cai, Z.H.; Liang, W.B. Template synthesis of organic microtubules. J. Am. Chem. Soc. 1990, 112, 8976-8977.

68. Beadle, P.; Armes, S.P.; Gottesfeld, S.; Mombourquette, C.; Houlton, R.; Andrews, W.D.; Agnew, S.F. Electrically conductive polyaniline copolymer latex composites. Macromolecules 1992, 25, 2526-2530.

69. Niu, Z.; Liu, J.; Lee, L.A.; Bruckman, M.A.; Zhao, D.; Koley, G.; Wang, Q. Biological templated synthesis of water-soluble conductive polymeric nanowires. Nano Lett. 2007, 7, 3729-3733.

70. Niu, Z.W.; Bruckman, M.A.; Li, S.Q.; Lee, L.A.; Lee, B.; Pingali, S.V.; Thiyagarajan, P.; Wang, Q. Assembly of tobacco mosaic virus into fibrous and macroscopic bundled arrays mediated by surface aniline polymerization. Langmuir 2007, 23, 6719-6724.

71. Shyh-Chyang, L.; Hsiao-hua, Y.; Wan, A.; Yu, H.; Ying, J.Y. A general synthesis for PEDOTcoated nonconductive materials and PEDOT hollow particles by aqueous chemical polymerization. Small 2008, 4, 2051-2058.

72. Luo, S.C.; Yu, H.H.; Wan, A.C.A.; Han, Y.; Ying, J.Y. A general synthesis for PEDOT-coated nonconductive materials and PEDOT hollow particles by aqueous chemical polymerization. Small 2008, 4, 2051-2058.

73. Fu, G.D.; Zhao, J.P.; Sun, Y.M.; Kang, E.T.; Neoh, K.G. Conductive hollow nanospheres of polyaniline via surface-initiated atom transfer radical polymerization of 4-vinylaniline and oxidative graft copolymerization of aniline. Macromolecules 2007, 40, 2271-2275.

74. Niu, Z.W.; Yang, Z.H.; Hu, Z.B.; Lu, Y.F.; Han, C.C. Polyaniline-silica composite conductive capsules and hollow spheres. Adv. Funct. Mater. 2003, 13, 949-954.

75. Feng, X.M.; Mao, C.J.; Yang, G.; Hou, W.H.; Zhu, J.J. Polyaniline/Au composite hollow spheres: Synthesis, characterization, and application to the detection of dopamine. Langmuir 2006, 22, 4384-4389.

76. Wu, Q.; Wang, Z.Q.; Xue, G. Controlling the structure and morphology of monodisperse polystyrene/polyaniline composite particles. Adv. Funct. Mater. 2007, 17, 1784-1789.

77. Zhang, Z.M.; Sui, J.; Zhang, L.J.; Wan, M.X.; Wei, Y.; Yu, L.M. Synthesis of polyaniline with a hollow, octahedral morphology by using a cuprous oxide template. Adv. Mater. 2005, 17, 2854-2857.

78. Cai, Z.H.; Lei, J.T.; Liang, W.B.; Menon, V.; Martin, C.R. Molecular and supermolecular origins of enhanced electronic conductivity in template-synthesized polyheterocyclic fibrils. 1. supermolecular effects. Chem. Mat. 1991, 3, 960-967.

79. Liu, C.; Martin, C.R. Composite membranes from photochemical-synthesis of ultrathin polymerfilms. Nature 1991, 352, 50-52. 
80. Penner, R.M.; Martin, C.R. Controlling the morphology of electronically conductive polymers. J. Electrochem. Soc. 1986, 133, 2206-2207.

81. Martin, C.R. Nanomaterials - a membrane-based synthetic approach. Science 1994, 266, 1961-1966.

82. Martin, C.R.; Parthasarathy, R.; Menon, V. Template synthesis of electronically conductive polymers preparation of thin-films. Electrochim. Acta 1994, 39, 1309-1313.

83. Martin, C.R. Template synthesis of electronically conductive polymer nanostructures. Accounts Chem. Res. 1995, 28, 61-68.

84. Mohammadi, A.; Lundstrom, I.; Inganas, O. Synthesis of conducting polypyrrole on a polymeric template. Synth. Met. 1991, 41, 381-384.

85. Parthasarathy, R.V.; Martin, C.R. Synthesis of polymeric microcapsule arrays and their use for enzyme immobilization. Nature 1994, 369, 298-301.

86. Martin, C.R. Membrane-based synthesis of nanomaterials. Chem. Mat. 1996, 8, 1739-1746.

87. De Vito, S.; Martin, C.R. Toward colloidal dispersions of template-synthesized polypyrrole nanotubules. Chem. Mat. 1998, 10, 1738-1741.

88. Park, D.H.; Kim, M.; Kim, M.S.; Kim, D.C.; Song, H.; Kim, J.; Joo, J. Electrochemical synthesis and nanoscale photoluminescence of poly(3-butylthiophene) nanowire. Electrochem. Solid State Lett. 2008, 11, K69-K72.

89. Joo, J.; Kim, B.H.; Park, D.H.; Kim, H.S.; Seo, D.S.; Shim, J.H.; Lee, S.J.; Ryu, K.S.; Kim, K.; Jin, J.I.; Lee, T.J.; Lee, C.J. Fabrication and applications of conducting polymer nanotube, nanowire, nanohole, and double wall nanotube. Synth. Met. 2005, 153, 313-316.

90. Granstrom, M.; Carlberg, J.C.; Inganas, O. Electrically conductive polymer fibers with mesoscopic diameters. 2. studies of polymerization behavior. Polymer 1995, 36, 3191-3196.

91. Kuwabata, S.; Martin, C.R. Mechanism of the amperometric response of a proposed glucose sensor-based on a polypyrrole-tubule-impregnated membrane. Anal. Chem. 1994, 66, 2757-2762.

92. Martin, C.R.; Parthasarathy, R.V. Polymeric microcapsule arrays. Adv. Mater. 1995, 7, 487-488.

93. Parthasarathy, R.V.; Martin, C.R. Enzyme and chemical encapsulation in polymeric microcapsules. J. Appl. Polym. Sci. 1996, 62, 875-886.

94. Kim, H.S.; Park, D.H.; Lee, Y.B.; Kim, D.C.; Kim, H.J.; Kim, J.; Joo, J. Doped and de-doped polypyrrole nanowires by using a BMIMPF6 ionic liquid. Synth. Met. 2007, 157, 910-913.

95. Koo, Y.K.; Kim, B. H.; Park, D.H.; Joo, J. Electrochemical polymerization of polypyrrole nanotubes and nanowires in ionic liquid. Mol. Cryst. Liquid Cryst. 2004, 425, 333-338.

96. Mohammadi, A.; Paul, D.W.; Inganas, O.; Nilsson, J.O.; Lundstrom, I. Electrically conductive composite prepared by template polymerization of pyrrole into a complexed polymer. J. Polym. Sci. Pol. Chem. 1994, 32, 495-502.

97. Qiu, H.J.; Zhai, J.; Li, S.H.; Jiang, L.; Wan, M.X. Oriented growth of self-assembled polyaniline nanowire arrays using a novel method. Adv. Funct. Mater. 2003, 13, 925-928.

98. Xiao, R.; Cho, S., II; Liu, R.; Lee, S.B. Controlled electrochemical synthesis of conductive polymer nanotube structures. J. Am. Chem. Soc. 2007, 129, 4483-4489.

99. Lahav, M.; Weiss, E.A.; Xu, Q.B.; Whitesides, G.M. Core-shell and segmented polymer-metal composite nanostructures. Nano Lett. 2006, 6, 2166-2171. 
100. Dai, T.Y.; Lu, Y. Water-soluble methyl orange fibrils as versatile templates for the fabrication of conducting polymer microtubules. Macromol. Rapid Commun. 2007, 28, 629-633.

101. Fei, J.B.; Cui, Y.; Yan, X.H.; Yang, Y.; Wang, K.W.; Li, J.B. Controlled Fabrication of polyaniline spherical and cubic shells with hierarchical nanostructures. ACS Nano 2009, 3, 3714-3718.

102. Duvail, J.L.; Long, Y.; Retho, P.; Louarn, G.; De Pra, L.D.; Demoustier-Champagne, S. Enhanced electroactivity and electrochromism in PEDOT nanowires. Mol. Cryst. Liquid Cryst. 2008, 485, 835-842.

103. Duvail, J.L.; Long, Y.Z.; Cuenot, S.; Chen, Z.J.; Gu, C.Z. Tuning electrical properties of conjugated polymer nanowires with the diameter. Appl. Phys. Lett. 2007, 90, 102114:1-102114:3.

104. Duvail, J.L.; Retho, P.; Fernandez, V.; Louarn, G.; Molinie, P.; Chauvet, O. Effects of the confined synthesis on conjugated polymer transport properties. J. Phys. Chem. B 2004, 108, 18552-18556.

105. Menon, V.P.; Lei, J.T.; Martin, C.R. Investigation of molecular and supermolecular structure in template-synthesized polypyrrole tubules and fibrils. Chem. Mat. 1996, 8, 2382-2390.

106. Duvail, J.L.; Retho, P.; Godon, C.; Marhic, C.; Louarn, G.; Chauvet, O.; Cuenot, S.; Pra, N.; Demoustier-Champagne, S. Physical properties of conducting polymer nanofibers. Synth. Met. 2003, 135, 329-330.

107. Long, Y.Z.; Yin, Z.H.; Li, M.M.; Gu, C.Z.; Duvail, J.L.; Jin, A.Z.; Wan, M.X. Current-voltage characteristics of individual conducting polymer nanotubes and nanowires. Chin. Phys. B 2009, 18, 2514-2522.

108. Long, Y.Z.; Duvail, J.L.; Chen, Z.J.; Jin, A.Z.; Gu, C.Z. Electrical properties of isolated poly(3,4-ethylenedioxythiophene) nanowires prepared by template synthesis. Polym. Adv. Technol. 2009, 20, 541-544.

109. Long, Y.Z.; Duvail, J.L.; Wang, Q.T.; Li, M.M.; Gu, C.Z. Electronic transport through crossed conducting polymer nanowires. J. Mater. Res. 2009, 24, 3018-3022.

110. Orgzall, I.; Lorenz, B.; Ting, S.T.; Hor, P.H.; Menon, V.; Martin, C.R.; Hochheimer, H.D. Thermopower and high-pressure electrical conductivity measurements of template synthesized polypyrrole. Phys. Rev. B 1996, 54, 16654-16658.

111. Penner, R.M.; Vandyke, L.S.; Martin, C.R. Electrochemical evaluation of charge-transport rates in polypyrrole. J. Phys. Chem. 1988, 92, 5274-5282.

112. Gustafsson, J.C.; Liedberg, B.; Inganas, O. In-situ spectroscopic investigations of electrochromism and ion-transport in a poly(3,4-ethylenedioxythiophene) electrode in a solidstate electrochemical-cell. Solid State Ion. 1994, 69, 145-152.

113. Nystrom, G.; Razaq, A.; Stromme, M.; Nyholm, L.; Mihranyan, A. Ultrafast all-polymer paperbased batteries. Nano Lett. 2009, 9, 3635-3639.

114. Nishizawa, M.; Mukai, K.; Kuwabata, S.; Martin, C.R.; Yoneyama, H. Template synthesis of polypyrrole-coated spinel $\mathrm{LiMn}_{2} \mathrm{O}_{4}$ nanotubules and their properties as cathode active materials for lithium batteries. J. Electrochem. Soc. 1997, 144, 1923-1927. 
115. Liu, R.; Lee, S. B. MnO2/Poly(3,4-ethylenedioxythiophene) coaxial nanowires by one-step coelectrodeposition for electrochemical energy storage. J. Am. Chem. Soc. 2008, 130, 2942-2943.

116. Cheng, F.Y.; Tang, W.; Li, C.S.; Chen, J.; Liu, H.K.; Shen, P.W.; Dou, S.X. Conducting poly(aniline) nanotubes and nanofibers: Controlled synthesis and application in lithium/poly(aniline) rechargeable batteries. Chem.-Eur. J. 2006, 12, 3082-3088.

117. Li, G.C.; Zhang, C.Q.; Peng, H.R.; Chen, K.Z. One-dimensional $\mathrm{V}_{2} \mathrm{O}_{5} @$ Polyaniline core/shell nanobelts synthesized by an in situ polymerization method. Macromol. Rapid Commun. 2009, 30, 1841-1845.

(C) 2010 by the authors; licensee MDPI, Basel, Switzerland. This article is an Open Access article distributed under the terms and conditions of the Creative Commons Attribution license (http://creativecommons.org/licenses/by/3.0/). 